Gut, 1986, 27, S1, 103-110

\title{
Branched chain amino acids in liver disease: fact or fantasy?
}

\author{
D B A SILK \\ Department of Gastroenterology and Nutrition, Central Middlesex Hospital, London
}

It has been recognised for many years that patients with chronic parenchymal liver disease are malnourished. In a recent report O'Keefe et al found that on formal testing a considerable number of their patients had clinical, biochemical, haematological and immunological variables thought to be indicative of protein calorie malnutrition, ${ }^{1}$ and furthermore, their data suggested a link between malnutrition, energy, sepsis and mortality in their patients. ${ }^{1}$

Poor dietary intake is almost certainly one of the principal causes of nutritional deficiencies in chronic liver disease. This may arise on account of associated anorexia and nausea and also because dietary protein intake is often restricted for therapeutic reasons as part of the management of hepatic encephalopathy.

Evidence is accumulating, which suggests that nutritional deficiencies also arise on account of impaired digestion and absorption of nutrients. To date, pancreatic exocrine insufficiency has been shown in patients with cirrhosis, ${ }^{2}$ as well as malabsorption of D-xylose, thiamine, folic acid and fat. ${ }^{3}$

Specific changes in whole body protein turnover rates may also contribute to the impaired nutritional state seen in patients without cirrhosis. Thus although whole body protein synthesis rates in cirrhosis seem to be normal, rates of breakdown are increased in patients with and without encephalopathy. ${ }^{4}$

\section{Hepatic encephalopathy: the dilemma}

It is a feature of the natural history of the disease that most patients with hepatic cirrhosis will develop hepatic encephalopathy and coma at some stage during the course of their illness. The commonest precipitating causes are infection, electrolyte abnormalities (often caused by diuretic abuse), variceal haemorrhage, sedative abuse and constipation.

One of the greatest dilemmas in clinical hepato-

Correspondence to: Dr D B A Silk. Department of Gastroenterology and Nutrition. Central Middlesex Hospital. London NW10 7NS. England. logy is that of often being forced to restrict protein intake in an already malnourished patient with cirrhosis in an attempt to improve or prevent the onset of hepatic encephalopathy. While the mental state of these patients may improve by dietary protein restriction, their nutritional state may deteriorate. Periodically malnutrition may be one of the reasons why these patients are unduly susceptible to developing infection and, as is widely known, infection is one of the most common precipitating causes of hepatic encephalopathy."

NUTRITIONAL SUPPORT IN THE ABSENCE OF HEPATIC ENCEPHALOPATHY

When there is no impairment of mental function the nutritional state of malnourished patients with parenchymal liver disease can be improved by standard means. Whenever possible, this should be done by increasing normal dietary intake with appropriate supplementation with electrolytes, vitamins, and haematinics. If for any reason nutrients cannot be given in the form of a normal diet then these patients should receive nutritional support via the enteral or parenteral route. The normal principles for determining whether nutritional support should be provided by the enteral or parenteral route should be adhered to and, in general, as long as gastrointestinal function is normal or near normal, attempts should be made to provide nutritional support via the enteral route, and the use of parenteral nutrition should be restricted to those patients whose gastrointestinal function is severely impaired.

NUTRITIONAL SUPPORT IN THE PRESENCE OF HEPATIC ENCEPHALOPATHY

Although the pathogenesis of hepatic encephalopathy has not been fully elucidated, for many years high serum concentrations of ammonia have been thought to play a major part and accordingly the rationale of standard "anti-coma" treatment has been to lower serum ammonia concentrations. A major source of ammonia formation is colonic bacterial ureolysis, and the cornerstone of treatment - 
namely, protein restriction - has been aimed at reducing the rate of urea synthesis, treatment with neomycin, lactulose, or lactitol ${ }^{67}$ being aimed at further reducing the colonic production and absorption of ammonia.

In practice, therefore, many comatosed patients receive peripheral infusion of $10 \%$ dextrose as their sole source of energy and a maximum of $20 \mathrm{~g}$ protein via a nasogastric tube as their sole source of nitrogen, vitamin supplementations usually being given in the form of daily Parentrovite injections. If the patient has ascites volume intake may be restricted to $1 \cdot 0-1.5 \mathrm{l} /$ day, so that total energy intake may be as low as $400 \mathrm{kcal} / \mathrm{day}$. The net result of this standard approach is that it has not only been impossible to improve the nutritional state of the malnourished and encephalopathic patients with cirrhosis, but as implied above, the nutritional state of these patients actually deteriorates during treatment.

During the past decade much research has been directed towards examining the role of altered amino acid metabolism in the pathogenesis of hepatic encephalopathy, in particular, the relation between imbalances of plasma amino acid profiles and brain false neurotransmitter synthesis. New approaches to the management of malnutrition and treatment of the encephalopathy in patients with cirrhosis have emerged, based on the use of branched chain enriched amino acid formulations. The aim of this paper is to discuss some of the basic research that has promoted the new approaches to treatment and to review results of trials that report clinical experiences.

\section{The role of circulating amino acid balances in the pathogenesis of hepatic encephalopathy}

A complete review of the biochemical mechanisms thought to have a role in the pathogenesis of hepatic encephalopathy is not relevant to the ensuing discussion, and the reader is referred elsewhere for this. ${ }^{8}$

Hepatic failure is associated with a considerable increase in plasma concentrations of aspartate, glutamate, phenylalanine, tyrosine, methionine and free tryptophan. ${ }^{8}$ Most attention has been focused on phenylalanine and tyrosine because of the precursor association with brain catecholamines, and on tryptophan, which is converted into the inhibitory neurotransmitter serotonin.

In chronic encephalopathy there is a two to four-fold rise in the plasma concentrations of the aromatic amino acids, together with a decrease in the plasma concentrations of the branched chain amino acids valine, leucine, and isoleucine. ${ }^{9} \mathrm{~A}$ combination of catabolism and impaired hepatocellular function is probably responsible. Raised plasma concentrations of glucagon stimulate muscle catabolism with release of amino acids for gluconeogenesis. ${ }^{10}$ When hepatic function is poor, however, the uptake and metabolism of plasma aromatic amino acids is impaired. In contrast, branched chain amino acids are preferentially metabolised in muscle and fat, and their low values can be explained by their enhanced uptake as a result of the hyperinsulinaemia. ${ }^{11}$ Concentrations of the aromatic amino acids are considerably raised in fulminant hepatic failure, but concentrations of branched chain amino acids are normal. ${ }^{12}$ This pattern is thought to arise largely from massive necrosis of liver cells with release of amino acids into the circulation; catabolism probably has a less important role.

RELATION TO FALSE NEUROTRANSMITTER HYPOTHESIS

Increased intracerebral concentrations of phenylalanine and tyrosine may result in the formation of "false neurotransmitter" amines, which are thought to displace the putative neurotransmitters from synaptosomes. Excess tyrosine is decarboxylated to tyramine, which is then converted by dopamine-Boxidase into octopamine, and phenylalanine is converted into phenylethylamine and thence into phenyethanolamine. Concentrations of octopamine and phenylethanolamine were found to be raised in the brains of animals in acute hepatic coma. ${ }^{13}$ Phenylalanine also competes with tyrosine for the enzyme tyrosine hydroxylase, and tyramine competes with dopamine for dopamine-B-oxidase, with the result that intracerebral formation of the normal stimulatory transmitters (dopamine and noradrenaline) may be reduced. ${ }^{14}$

Concentrations of amino acids in the brain depend on the integrity of the blood brain barrier and the activity of the carrier systems of amino acids, as well as on the plasma concentrations. The neutral amino acids are transported across the blood brain barrier by a common carrier, ${ }^{15}$ and there is usually competition between the aromatic and branched chain amino acids. ${ }^{16}$ Thus low circulating concentrations of branched chain amino acids, together with their lower affinity constants for the carrier, might be expected to favour transport into the brain of the aromatic amino acids. Concentrations of branched chain amino acids in the cerebrospinal fluid have been observed to be normal in animals during hepatic coma, despite low plasma concentrations, ${ }^{19}$ possibly as a result of increased activity of the carrier system. ${ }^{18}$

In acute liver failure the blood brain barrier is 
commonly disrupted and may enhance the cerebral effect of plasma amino acid imbalance. Zaki et al, ${ }^{19}$ by means of the Oldendorf technique, showed that the blood brain barrier is also disrupted in rats six weeks after a portacaval anastomosis. Brain uptake of $\mathrm{L}-\left({ }^{14} \mathrm{C}\right)$ glucose, D- $\left({ }^{14} \mathrm{C}\right)$ sucrose, and $\left({ }^{14} \mathrm{C}\right)$ insulin, substances which do not normally cross the blood brain barrier were all increased, in addition to a selective increase in the uptake of neutral amino acids.

Further supportive evidence for a role of the aromatic amino acids in the pathogenesis of hepatic encephalopathy has arisen from a potentially important study in normal dogs. ${ }^{20}$ Intracarotid infusion of $1 \%$ tryptophan and $1 \%$ or $1.5 \%$ phenylalanine resulted in a neurological deterioration clinically, which resembled hepatic encephalopathy, culminating in coma. When a branched chain amino acid mixture $(0.63 \%$ leucine $+0.4 \%$ isoleucine $+0.46 \%$ valine) was added to the infusate, coma did not occur. The data were interpreted on the basis that the addition of branched chain amino acids may have prevented coma by competing with the aromatic acids for transport across the blood brain barrier. ${ }^{20}$

It seems increasingly clear that a unified hypothesis to explain the pathogenesis of hepatic encephalopathy in cirrhosis is untenable. In their more recent hypothesis Fischer et al ${ }^{2 \mathrm{i}}$ proposed that hyperammonaemia increases the influx of ammonia into the brain where it reacts with glutamic acid to form glutamine, which then effluxes from the brain using the same carrier system that mediates the influx into the brain of the other neutral amino acids that are the precursors for synthesis of the false neurotransmitters. Thus there may be a link between the ammonia toxicity and the false neurotransmitter hypothesis. ${ }^{21}$

Against the theory of the false neurotransmitter is that octopamine instilled into the ventricles of rats produced a striking increase in its concentration in the brain and a fall in whole brain dopamine and noradrenaline to one tenth of normal values, without any disturbance in consciousness. ${ }^{22}$ In a study in which brain catecholamines were measured after death in patients with cirrhosis and encephalopathy no reduction in dopamine or noradrenaline concentrations was found, and octopamine concentrations were decreased compared with those of patients with cirrhosis who were not encephalopathic at the time of death. ${ }^{23}$

\section{Branched chain amino acid treatment of hepatic encephalopathy}

Fischer et al were the first to propose that the primary treatment of hepatic encephalopathy in cirrhosis might be enhanced by normalising circulating amino acid profiles in their patients. ${ }^{24}$ Subsequently, some would argue that the emphasis of this approach has shifted from primary treatment of the encephalopathy to the safe provision of nutritional support, which at the same time does not have the expected deleterious effect on the neuropsychiatric state of these patients. Fischer's group devised a specially formulated amino acid solution for intravenous use that contained considerably decreased amounts of phenylalanine, tyrosine, tryptophan, methionine and glycine and increased amounts of the branched chain amino acids leucine, isoleucine, and valine, as well as arginine. After showing that survival in encephalopathic dogs receiving this formulation was appreciably increased compared with dogs receiving a standard intravenous formulation of amino acids, ${ }^{25}$ clinical studies were started.

Results were encouraging, for not only did infusion of the amino acid mixture correct plasma amino acid profiles of patients, but neuropsychiatric state seemed to improve during treatment. ${ }^{26}$ In passing, they found that positive nitrogen balance was achieved. $^{26}$

The studies conducted by Fischer ${ }^{26}$ have been criticised because they were not controlled. The composition of amino acid solution devised by Fischer et al (FO80) was based purely on extrapolations made from experimental data derived from their animal and clinical studies. In retrospect, certain aspects of the formulation are open to criticism. With the aim of normalising the plasma amino acid profile of the patients with hepatic encephalopathy, $34 \cdot 6 \%$ of the amino acid content of FO80 was constituted with branched chain amino acids (leucine $13.4 \%$, valine $10 \cdot 2 \%$, isoleucine $11.0 \%$ ). Later studies have shown that it is the intravenous infusion of leucine, rather than valine, or isoleucine that lowers the concentrations of the aromatic amino acids and methionine. ${ }^{27}$ It can be argued, therefore, that the proportions of the individual branched chain amino acids are not necessarily ideal in the formulation. FO80 contains no tyrosine or cysteine, and in some patients with cirrhosis this has been shown to prevent achievement of positive nitrogen balance despite provision of adequate essential amino acid precursors. ${ }^{28}$ Finally, the rationale for infusing tryptophan, phenylalanine, and methionine in patients with hepatic encephalopathy, even in small amounts, is questionable. ${ }^{29}$

Interpretation of the results of the clinical studies $^{29}$ is also confused because FO80 contains relatively high proportions of arginine $(7.5 \%)$. There is evidence to suggest that arginine (or 
ornithine, the precursor as well as the metabolic product of arginine), may counteract hyperammonaemia by stimulating ureagenesis. ${ }^{30}$ It cannot be concluded with certainty, therefore, that the beneficial clinical responses attributed to $\mathrm{FO} 80$ are not due to the increases in arginine content.

As mentioned above, the studies by Fischer have stimulated much further clinical research into mixtures of amino acids rich in branched chain amino acids and deficient in aromatic amino acids. Conn ${ }^{31}$ pointed out how difficult it is to draw conclusions from the data, particularly those derived from uncontrolled trials. The controlled trials that have been performed have, moreover, evaluated different amino acid mixtures administered in different ways, using different end products, to patients with different types and degrees of encephalopathy. Not surprisingly, different results were obtained. Can any conclusions be drawn about the therapeutic efficacy of branched chain amino acids in portal systemic encephalopathy? In my opinion the answer to this is a qualified "yes," but only if certain ground rules are accepted. Firstly, only controlled trials must be considered, and secondly, it is inappropriate to compare directly results of studies carried out in patients with cirrhosis who present with clearly different clinical types of encephalopathy - that is, latent, chronic, and acute forms.

The ensuing analysis has been restricted to seven controlled trials that have been reported fully in English or American scientific journals. ${ }^{31-37}$ One of these studies was restricted purely to patients with latent (subclinical) portal systemic encephalopathy ${ }^{36}$ three to patients with chronic portal systemic encephalopathy, ${ }^{31-33}$ and three patients with acute portal systemic encephalopathy. ${ }^{34} 35.37$

\section{LATENT (SUBCLINICAL) PORTAL SYSTEMIC} ENCEPHALOPATHY (Table 1)

Egberts et al are the only group to have restricted their studies to patients with cirrhosis who have never been clinically encephalopathic (all grade 0 ) and who have never received dietary restriction as part of clinical management. ${ }^{36}$ Latent (subclinical) portal systemic encephalopathy was diagnosed using an extensive psychometric test programme.

Patients received a defined diet of $35 \mathrm{cal} / \mathrm{kg}$ a day containing $1 \mathrm{~g}$ of protein $/ \mathrm{kg} /$ day. Branched chain amino acids or casein in a dose of $0.25 \mathrm{~g} / \mathrm{kg}$ a day was also given in a cross over fashion for one week. Semiquantitative nitrogen balance increased during both treatments, with a tendency of a larger increase during branched chain amino acid treatment. At the same time ammonia concentration tended to decrease during branched chain amino acid treatment. Taking into account the crossover design, appreci-
Table 1 Controlled trial of branched chain amino acids in latent (subclinical) portal systemic encephalopathy ${ }^{\dagger}$

\begin{tabular}{|c|c|}
\hline \multicolumn{2}{|l|}{ From Egberts et $a l^{36}$} \\
\hline Trial design & Double blind cross over $(n=22)^{*}$ \\
\hline Method of & \\
\hline & Oral \\
\hline Duration of treatment & 7 days \\
\hline Test & $\begin{array}{l}\text { Dietary protein } 1 \mathrm{~g} / \mathrm{kg}^{-1} / \mathrm{day}^{-1} \\
+ \text { BCAA } 0 \cdot 25 \mathrm{~g} \mathrm{~kg}^{-1} / \mathrm{day}^{-1} \\
\text { (Leucine } 43 \% \text { valine } 28.5 \% \text { isoleucine } \\
28.5 \% \text { ) }\end{array}$ \\
\hline Control & $\begin{array}{l}\text { Dietary protein } 1 \mathrm{~g} / \mathrm{kg}^{-1} / \mathrm{day}^{-1} \\
\quad+\text { Cascin } 0 \cdot 25 \mathrm{~g} / \mathrm{kg}^{-1} / \mathrm{day}^{-1}\end{array}$ \\
\hline Nitrogen balance & Positive both groups \\
\hline Encephalopathy & Improvement \\
\hline & Test $v$ control \\
\hline
\end{tabular}

†Analysis restricted to studies published in full in English language scientific journals.

* 14/22 patients received lactulose throughout both study periods.

able improvements attributable to branched chain amino acid treatment could be shown in psychomotor functions (line tracing, tapping, steadiness, auditory reaction time), attention (digit table), and practical intelligence (digit symbol, number connection test).

It must be appreciated that the study only lasted one week so that the benefits shown must be considered at best to be very short term.

\section{CHRONIC PORTAL SYSTEMIC ENCEPHALOPATHY (Table 2)}

Three groups have addressed the question of whether branched chain amino acid supplementation has a beneficial effect on the mental state of patients with cirrhosis and chronic portal systemic encephalopathy. ${ }^{31-33}$ Two trials, each with a small number of patients, were cross over in design ${ }^{32} .33$ and the third was a larger double blind randomised trial. ${ }^{31}$ Entry criteria differed in that in the cross over trial of Eriksson et al ${ }^{32}$ all patients had clinical encephalopathy (grade I-II) on entry, although only four of seven were receiving a $40 \mathrm{~g}$ protein restricted diet. All patients in the two other trials ${ }^{31}{ }^{33}$ were on a $40 \mathrm{~g}$ protein restricted diet on account of chronic portal systemic encephalopathy and were either in grade 0 or stable grade I encephalopathy on entry.

These important differences in trial design and entry criteria make it impossible directly to compare results. Furthermore, as Table 2 shows, branched chain amino acid supplements were administered in the pure form in one trial ${ }^{3 / 2}$ and as the amino acid diet Hepaticaid in the two others. ${ }^{31}{ }^{3.3}$

In neither of the two small and short term cross over trials ${ }^{32} .3 .3$ was there a suggestion that branched chain amino acid supplements had any appreciably 
Table 2 Controlled trials of branched chain amino acids in chronic portal systemic encephalopathy*

\begin{tabular}{|c|c|c|c|}
\hline Reference & Eriksson et $a l^{32}$ & McGhee et $a l^{3,3}$ & Horst et al \\
\hline Trial design & $\begin{array}{l}\text { Double blind } \\
\text { randomised crossover } \\
(n=7)\end{array}$ & $\begin{array}{l}\text { Randomised cross } \\
\text { over }(n=4)\end{array}$ & $\begin{array}{l}\text { Double blind randomised } \\
(n=17 \text { for test })(n=20 \text { for } \\
\text { controls) }\end{array}$ \\
\hline Coma grade on entry & I-II & $0 \dagger$ & $0-1 \div$ \\
\hline Method of administration & Oral & Oral & Oral \\
\hline Duration of treatment & 14 days $\ddagger$ & 11 days $\ddagger$ & 4 weeks \\
\hline \multicolumn{4}{|l|}{ Treatment } \\
\hline Test & 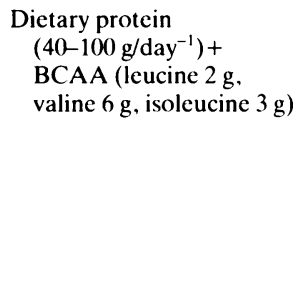 & $\begin{array}{l}20 \mathrm{~g} \text { casein diet }+ \\
30 \mathrm{~g} \mathrm{BCAA} \text { enriched } \\
\text { amino acid diet } \\
\text { (Hepaticaid; leucine } 4 \cdot() \mathrm{g} \text {, } \\
\text { valine } 3 \cdot 1 \mathrm{~g} \text {, isoleucine } 3 \cdot 3 \mathrm{~g} \text { ) }\end{array}$ & $\begin{array}{l}\text { Weck } 120 \text { g dictary protein } \\
\text { Weck } 220 \text { g dictary protein }+ \\
20 \text { g BCAA enriched amino } \\
\text { acid diet (Hepaticaid, } \\
\text { leucine } 13 \cdot 4 \% \text {, valine } 10 \cdot 2 \% \text {, } \\
\text { isoleucine } 11 \cdot(0 \%) \\
\text { Weck } 320 \text { g dietary protein }+ \\
40 \text { g hepaticaid } \\
\text { Week } 420 \text { g dictary protein }+ \\
60 \text { g hepaticaid }\end{array}$ \\
\hline Control & $\begin{array}{l}\text { Dietary protein } \\
\left(40-100 \mathrm{~g}^{\left.- \text {day }^{-1}\right)}+\right. \\
\text { placebo (four patients } \\
\text { on } 40 \mathrm{~g} \text { protein } \\
\text { restriction also } \\
\text { maintained on lactulose } \\
\text { throughout both study } \\
\text { periods) }\end{array}$ & Casein diet $(50 \mathrm{~g})$ & $\begin{array}{l}\text { Week } 120 \text { g dietary protein } \\
\text { Week } 240 \text { g dictary protcin } \\
\text { Weck } 360 \text { g dietary protein } \\
\text { Week } 480 \text { g dictary protein }\end{array}$ \\
\hline \multicolumn{4}{|l|}{ Results } \\
\hline Nitrogen balance & & Positive & $\begin{array}{l}\text { Positive both groups } \\
\text { weeks } 3 \text { and } 4\end{array}$ \\
\hline Encephalopathy & NS & NS & $\begin{array}{l}\text { Frequency of encephalopathy } \\
\text { greater in test } v \\
\text { control patients }\end{array}$ \\
\hline
\end{tabular}

†All had had chronic recurrent portal systemic encephalopathy and had required restriction of protein to $4(0) \mathrm{g} / \mathrm{day}{ }^{-1}$ or less.

*Analysis restricted to studies published in full in English language scientific journals.

$\ddagger$ Duration of treatment for each study period.

beneficial effect on the mental state of the patients studied.

In the longer term and larger trial of Horst $e a^{31}$ there seemed to be a distinct advantage of the branched chain amino acid supplemented diet, Hepaticaid. Thus although Hepaticaid was equally effective at inducing positive nitrogen balance as an equivalent amount of whole protein, encephalopathy was induced far less often during the four weeks of the trial. ${ }^{31}$ If these observations are confirmed (and they were not made in the cross over study of McGhee et $\mathrm{l}^{33}$ ) then the potential role of branched chain amino acids in chronic portal systemic encephalopathy will have shifted from that of a primary therapeutic agent for the encephalopathy to a means of more safely improving the nutritional state of these patients: a clear change of emphasis compared with the original claims.

3 ACUTE PORTAL SYSTEMIC ENCEPHALOPATHY (Table 3)

In three simple randomised controlled trials ${ }^{34} 3537$ branched chain amino acids were administered parenterally. It is difficult to compare the results of all three directly, because in the two earlier trials $^{34.35}$ branched chain amino acids represented the sole source of nitrogen, whereas in the third ${ }^{37}$ the branched chain amino acids enriched amino acid solution FO80 was given. The three trials examined two end points - namely, the effect on encephalopathy and effect on mortality.

In the trials conducted by Rossi-Fanelli and Wahren ${ }^{34} 35$ no significant benefit of branched chain amino acids was seen either in respect of encephalopathy or mortality. The trials were very similar in design except that Rossi-Fanelli et al ${ }^{34}$ entered their encephalopathic patients into the trial immediately, whereas patients in the Wahren trial were treated by standard means for 24 hours before randomisation. ${ }^{35}$ (Table 3) Control patients in the Rossi-Fanelli trial ${ }^{34}$ received lactulose whereas those in the other trial ${ }^{3.5}$ did not. It should be emphasised that in both trials considerable quantities of glucose were given to both the test and control patients (less in the 
Table 3 Controlled trials of branched chain amino acids in patients with cirrhosis and acute portal systemic encephalopathy ${ }^{\dagger}$

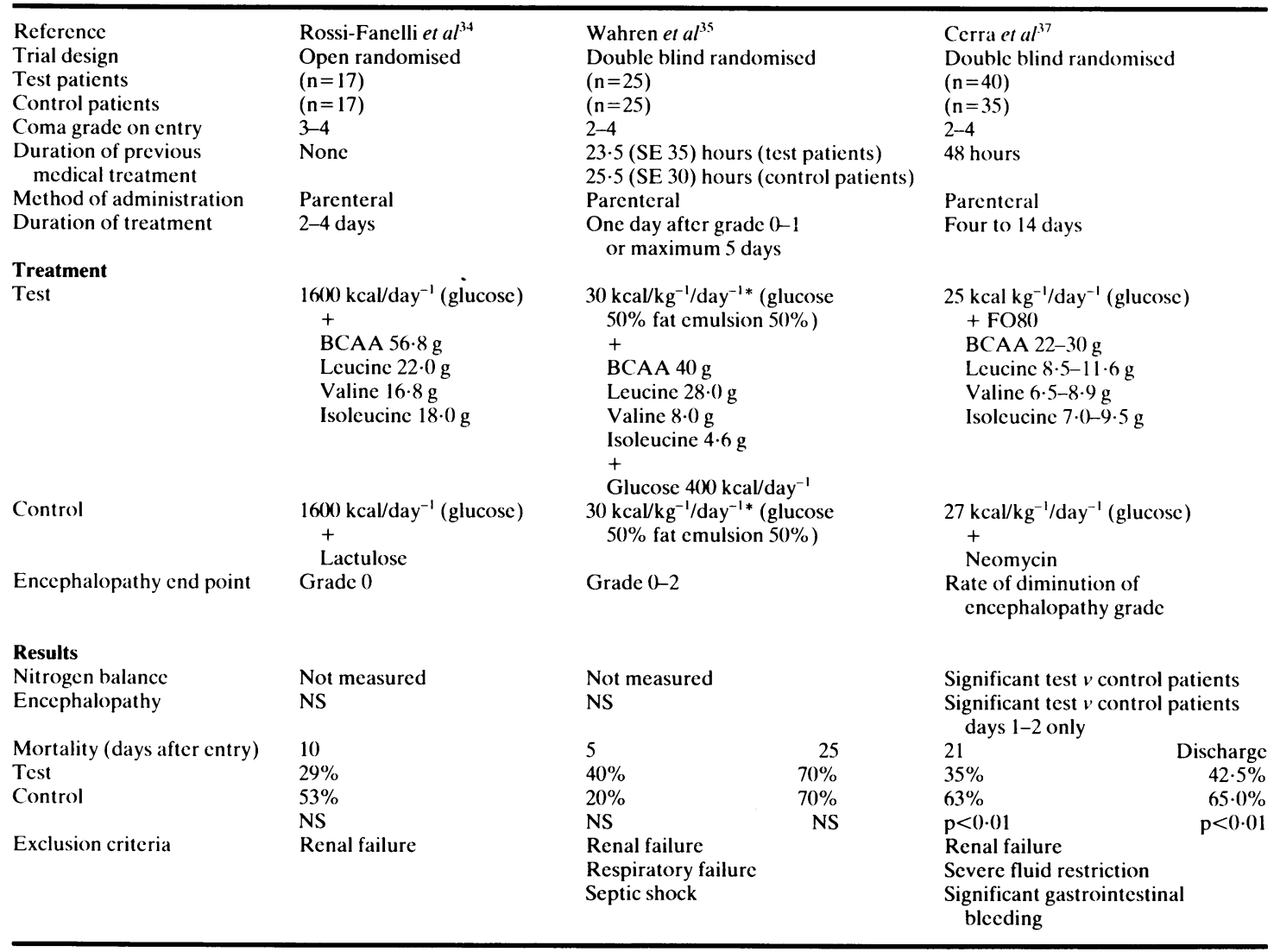

†Analysis restricted to studies published in full in English language scientific journals.

${ }^{*}$ Eight patients (five test, three control) received lactolose or neomycin, or both.

Wahren trial. ${ }^{35}$ ) On a theoretical basis glucose infusion would be expected to raise circulating insulin concentrations, which in turn would be expected to promote uptake of branched chain amino acids into muscle, thereby lowering even further circulating branched chain amino acid concentrations.

According to the hypothesis under investigation this might be expected to worsen the encephalopathy, thereby biasing the results toward the test group. As there were no apparent benefits of parenterally administered branched chain amino acids $\left(40-56.8 \mathrm{~g} \mathrm{~d}^{-1}\right)$ in either or both test groups there would seem to be no justification for recommending the use of pure branched chain amino acid supplements in combination with glucose ${ }^{34}$ or glucose plus lipid $^{35}$ in patients with cirrhosis who develop episodes of acute encephalopathy, either on a scientific or cost effective ${ }^{38}$ basis.

At first sight the results of the Cerra trial ${ }^{37}$ are promising: a significantly beneficial effect of a parenterally administered branched chain amino acid enriched (22-30 $\left.\mathrm{g} \mathrm{d}^{-1}\right)$ amino acid mixture (FO80) on encephalopathy and mortality was claimed. With respect to encephalopathy, the differences were only significant between days 1 and 2 , and, if Cerra et $^{\mathrm{al}^{37}}$ had taken the same encephalopathy end point as Rossi-Fanelli $e a^{34} l^{34}$ and Wahren et $a l,{ }^{35}$ their difference would probably have not been significant. On balance, therefore, it seems premature to conclude that FO80 has a clinically important effect on acute episodes of encephalopathy in patients with cirrhosis. It is difficult, however, to get away from the fact that the 
mortality was lower in the group of patients receiving FO80 than in control patients.

Unlike the studies of Rossi-Fanelli et al,,$^{34}$ and Wahren et al, ${ }^{35}$ Cerra et al excluded patients whose encephalopathy was precipitated by significant gastrointestinal haemorrhage. ${ }^{37}$ Whether this influenced the results is difficult to say. Bleeding from oesophageal varices carries a high mortality ${ }^{39} 40$ and it is possible that if, as in the two other trials, such patients had been included, different results may have been obtained. Cerra et al did treat their control patients with neomycin ${ }^{37}$ so it can be concluded, albeit on the basis of a single trial, that intravenous infusion of FO80 in encephalopathic cirrhotic patients, whose coma had not been precipitated by significant gastrointestinal haemorrhage, confers a clinically significant benefit in respect of mortality. Whether the observed improvement in mortality was related merely to the provision of nutritional support or to the effect of branched chain amino acids per se cannot be determined, and further controlled trials with FO80 or related amino acid mixture are clearly required.

\section{Conclusion}

Further long term studies are required before any firm conclusions can be drawn about the clinical benefits of branched chain amino acid supplementation in patients with subclinical or latent encephalopathy. In patients with established chronic portal systemic encephalopathy branched chain amino acid supplemented amino acid mixtures seem to induce positive nitrogen balance to about the same degree as an equivalent amount of dietary protein, without inducing encephalopathy as often. Infusions of branched chain amino acids alone in patients with cirrhosis and acute encephalopathy do not seem to confer any advantage either in terms of encephalopathy or survival. In contrast, there is a suggestion that survival in the patients can be improved by administering a branched chain amino acid enriched amino acid mixture (FO80), at least if the encephalopathy is not precipitated by significant gastrointestinal haemorrhage.

\section{References}

1 O'Keefe SJD, El-Zayadi A, Carraher T, et al. Malnutrition and immune competence in patients with liver disease. 1980 Lancet ii: 615-7.

2 Van Goidseahoven GE, Henke WJ, Vacca JB, et al. Pancreatic function in cirrhosis of the liver. Am J Dig Dis 1963; 8: 160-6.

3 Mezey G. Intestinal function in chronic alcoholism. An NY Acad Sci 1975; 252: 215-22.

4 O'Keefe SJD, Abraham R, El-Zayadi A, et al.
Increased plasma tyrosine concentrations in patients with cirrhosis and fulminant hepatic failure associated with increased plasma tyrosine flux and reduced hepatic oxidation capacity. 1981. Gastroenterology 81: 1017-24.

5 Sherlock S. Hepatic encephalopathy. In Diseases of the liver and biliary system. Oxford: Blackwell Scientific Publications, 1981: 91-106.

6 Lanthier PL, Morgan MY. Lactitol in the treatment of chronic hepatic encephalopathy: an open comparison with lactulose. Gut 1985; 26: 415-20.

7 Patil DH, Westaby D, Mahida Y, et al. Comparison of lactulose and lactitol on ileal and colonic pH. Gut 1985; 26: 1125 .

8 Silk DBA. Pathophysiology of liver failure. In: Jewell DP, Shepherd HA, eds. Topics in gastroenterology 11 Oxford: Blackwell Scientific Publications. 1983.

9 Rosen HM, Yoshimura M, Hodgman JM, Fisher JE. Plasma amino acid patterns in hepatic encephalopathy of differing aetiology. Gastroenterology 1977; 72: 483-7.

10 Sherwin R, Yoshi P, Hendler R, Felix P, Conn HO. Hyperglucagon anaemia in Launnec's cirrhosis: the role of portal systemic shunting. New Engl J Med 1974; 290: $239-42$.

11 Munro HN, Fernstrom JD, Wurtman RJ. Insulin, plasma amino acid imbalance and hepatic coma. Lancet 1975; i: 722-4.

12 Chase RA, Davis M, Trewby PN, Silk DBA, Williams R. Plasma amino acid profiles in patients with fulminant hepatic failure treated by repeated polyacrylonitrate membrane haemodialysis. Gastroenterology 1978; 75: $1033-40$.

13 Rossi-Fanelli F, Smith AR, Cangiano C. Simultaneous determination of phenylethanolamine and octopamine in plasma and cerebrospinal fluid. In: Moosmain A, ed. Biochemistry of phenylethyl amines. New York: Raven Press, 1978:

14 Kopin IJ, Welse VK, Sedvall GC. Effect of false transmitters on norepinephrine synthesis. J Pharmacol Exp Ther 1969; 170: 246-52.

15 Oldendorf WH, Szabo J. Amino acid assignment to one of three blood-brain barrier amino acid carriers. Am J Physiol 1976; 230: 96-102.

16 Oldendorf WH. Brain uptake of radiolabelled amino acids, amines and hexoses after arterial injection. Am J Physiol 1971; 221: 1629.

17 Smith AR, Rossi-Fanneli F, Ziparo V. Alterations in plasma and cerebrospinal fluid of amino acids, amines and metabolites in hepatic coma. Ann Surg 1978; 187: 343-50.

18 James JH, Escourrou J, Fischer JE. Blood-brain neutral amino acid transport activity is increased after porto caval anastomosis. Sciences 1978; 200: 1395-7.

19 Zaki AE, Silk DBA, Williams R. Increases in bloodbrain barrier permeability after porto caval anastomosis. Gut 1981; 21: 900.

20 Rossi-Fanneli F, Freund H, Krause R, et al. Induction of coma in normal dogs by the infusion of aromatic amino acids and its prevention by the addition of branched chain amino acids. Gastroenterology 1982; 83: $664-71$. 
21 James JH, Ziparo V, Jeppson B, Fischer JE. Hyperammonaemia, plasma amino acid imbalance and bloodbrain amino acid transport: a unified theory of portal systemic encephalopathy. Lancet 1979; ii: 772-3.

22 Zieve L, Olsen RL. Can hepatic coma be caused by a reduction of brain noradrenaline or dopamine? Gut 1977; 18: 688-91.

23 Cuilleret G, Pomier Layrargues G, Pons F, Cadehac J, Michell $\mathrm{H}$. Changes in brain catecholamine levels in human cirrhotic hepatic encephalopathy. Gut 1981; 21: 565-9.

24 Fischer JE, Baldessarini RJ. Pathogenesis and therapy of hepatic coma. In: Popper $\mathrm{H}$, Schaffner E, eds. Progress of liver diseases. New York: Grune and Stratton, 1976.

25 Fischer JE, Funovics JM, Aguirre A, et al. The role of plasma amino acids in hepatic encephalopathy. Surgery 1975; 70: 276-90.

26 Fischer JE, Rosen HM, Ebeid AM, et al. The effect of normalization of plasma amino acids on hepatic encephalopathy in man. Surgery 1976; 80: 77-91.

27 Eriksson S, Hagenfeldt L, Wahren J. A comparison of the effects of intravenous infusion of individual branched chain amino acids on blood amino acid levels in man. Clin Sci 1981; 60: 95-100.

28 Rudman D, Kufner M, Ansley J. Hypotyrosinemia. Hypocystinemia, and failure to retain nitrogen during total parenteral nutrition of cirrhotic patients. Gastroenterology 1981; 81: 1025-35.

29 Walser M. Therapeutic aspects of branched-chain amino and keto acids. Clin Sci 1984; 66: 1-15.

30) Walser M. Urea cycle disorders and other hereditary hyperammonaemic syndromes. In: Stanbury JB, Wyngaarden JB, Fredrickson DS, Goldstein JL, Brown MS, eds. The metabolic basis of inherited disease. New York: McGraw-Hill, 1982: 402-38.

31 Horst D, Grace ND, Conn HO, et al. Comparison of dietary protein with an oral, branched chain-enriched amino acid supplement in chronic portal systemic encephalopathy. A randomised controlled trial. Hepatology 1984; 4: 279-87.

32 Eriksson LS, Person A, Wahren J. Branched chain amino acids in the treatment of chronic hepatic encephalopathy. Gut 1983; 23: 801-6.

33 McGhee A, Henderson JM, Millikan WJ, et al. Comparison of the effects of hepatic aid and a casein modular diet on encephalopathy, plasma amino acids and nitrogen balance in cirrhotic patients. Ann Surg 1983; 197: 288-93.

34 Rossi-Fanelli F, Riggio O, Cangiano $\mathrm{C}$, et al. Branched chain amino acids vs lactulose in the treatment of hepatic coma: a controlled study. Dig Dis Sci 1982; 27: 929-35.

35 Wahren J, Denis J, Desurmont P, et al. Is intravenous administration of branched chain amino acids effective in the treatment of hepatic encephalopathy? A multicenter study. Hepatology 1983; 3: 475-80.

36 Egberts EH, Schomerus H, Hamster W, Jurgens P. Branched chain amino acids in the treatment of latent portal systemic encephalopathy. A double blind placebo-controlled crossover study. Gastroenterology 1985; 88: 887-95.

37 Cerra FB, Cheung NK, Fischer JE, et al. Diseasespecific amino acid infusion (FO80) in hepatic encephalopathy: A prospective, randomised, double blind controlled trial. JPEN 1985; 9: 288-95.

38 Koretz RL. Nutritional support. How much for how much? Gut 1986; 27 (Suppl): 85-95.

39 Novis BH, Duys P, Barbezat GO, et al. Fibreoptic endoscopy and the use of Sengstaken tube in acute gastro-intestinal haemorrhage in patients with portal hypertension and varices. Gut 1976; 17: 258-63.

40 Clark AW, Westaby D, Silk DBA, et al. Prospective controlled trial of injection sclerotherapy in patients with cirrhosis and recent variceal haemorrhage. Lancet 1980; ii: $552-4$. 